\title{
Computed tomographic analysis of hemifacial spasm: narrowing of the posterior fossa as a possible facilitating factor for neurovascular compression
}

\author{
Hiroyuki Kamiguchi, Takayuki Ohira, Masato Ochiai, Takeshi Kawase
}

\begin{abstract}
Hemifacial spasm can be caused by vascular compression of the facial nerve at the root exit zone from the brainstem. Several case reports suggest that narrowing of the cerebellopontine angle cistern caused by Paget's disease, abnormal elevation of the petrous bone caused by hyperplasia, or contralateral acoustic neurinoma may increase the chance of vascular compression of the facial nerve. Therefore, posterior fossa narrowness has been evaluated in 34 patients with hemifacial spasm by measuring the petrous angle and pons diameter index to elucidate whether narrowing of the posterior fossa can act as a facilitating factor for neurovascular compression. The petrous angle in the hemifacial spasm group was significantly smaller than that in the control group, which consisted of 33 patients with an unruptured supratentorial aneurysm, and the pons diameter index in the hemifacial spasm group was significantly greater than that in the control group. These results indicate that the cerebellopontine angle cistern of patients with hemifacial spasm is narrower resulting in more crowded cranial nerves and vascular structures compared with patients without hemifacial spasm. The narrowness of the cerebellopontine angle cistern may be a possible factor in facilitating neurovascular compression in hemifacial spasm.
\end{abstract}

Department of Neurosurgery, School of Medicine, Keio University, 35 Shinanomachi, Shinjuku-ku, Tokyo 160, Japan

H Kamiguchi

T Ohira

M Ochiai

T Kawase

Correspondence to: Dr Hiroyuki Kamiguchi, Department of

Neurosciences, School of Medicine, Case Western Reserve University, 10900 Euclid Avenue, Cleveland OH 44106-4975, USA.

Received 25 March 1996 and in final revised form

1996

Accepted 3 December 1996 the petrous bone caused by hyperplasia, ${ }^{5}$ or contralateral acoustic neurinoma, ${ }^{6}$ suggesting that narrowing of the cerebellopontine angle cistern caused by these abnormalities may increase the chance of vascular compression of the facial nerve. Therefore, we have evaluated narrowing of the posterior fossa in patients with hemifacial spasm to elucidate whether it can act as a facilitating factor for neurovascular compression.

\section{Patients and methods PATIENT POPULATION}

Thirty four patients with symptomatic hemifacial spasm were operated on at Keio University Hospital between 1990 and 1995. In all patients in the hemifacial spasm group, vascular compression of the facial nerve was recognised at the root exit zone from the brainstem, and microvascular decompression was performed. The hemifacial spasm group consisted of eight men and 26 women, ranging in age from 25 to 74 (mean (SD) $53 \cdot 1$ (11.7) years). As a control group, 33 consecutive patients (10 men, 23 women, age range 31-72 (mean (SD) $54.2(8.2)$ years)) who were admitted to Keio University Hospital between 1993 and 1995 for evaluation of an unruptured supratentorial aneurysm less than 1.5 $\mathrm{cm}$ in diameter, were analysed. Patients with any other intracranial disorders were excluded from the control group. There were no significant differences between the hemifacial spasm and control groups in sex and age distribution, and all the patients in both groups were Japanese.

EVALUATION OF POSTERIOR FOSSA NARROWNESS BY CT

Head CT for all patients in this study was carried out as follows: meticulous positioning was conducted by taking a lateral scout view of the head so that axial CT was parallel to the orbitomeatal line. The slice thickness was $5 \mathrm{~mm}$ in the levels of the posterior cranial fossa.

To evaluate an elevation of the petrous bone toward the cerebellopontine angle cistern, an angle, referred to as the petrous angle, was employed. This angle was measured between two lines drawn from the median point of the posterior surface of the clivus to the posteromedial surface of the bilateral 

line, and the petrous angle and pons diameter index were measured. (A) The petrous angle was defined as an angle between two lines drawn from the median point of the surface of the bilateral petrous bones at the level of the internal auditory meatuses. (B) The distance between the posterior surface of the clivus and the floor of the fourth ventricle (CF) and the distance between the ventral surface of the pons and the floor of the fourth ventricle (PF) were measured along the midline on a $C T$ slice $10 \mathrm{~mm}$ auditory meatuses, and the pons diameter index was calculated as $P F / C F \times$ $100(\%)$.
Axial CT was done parallel to the orbitomeatal posterior surface of the clivus to the posteromedial above the level of internal

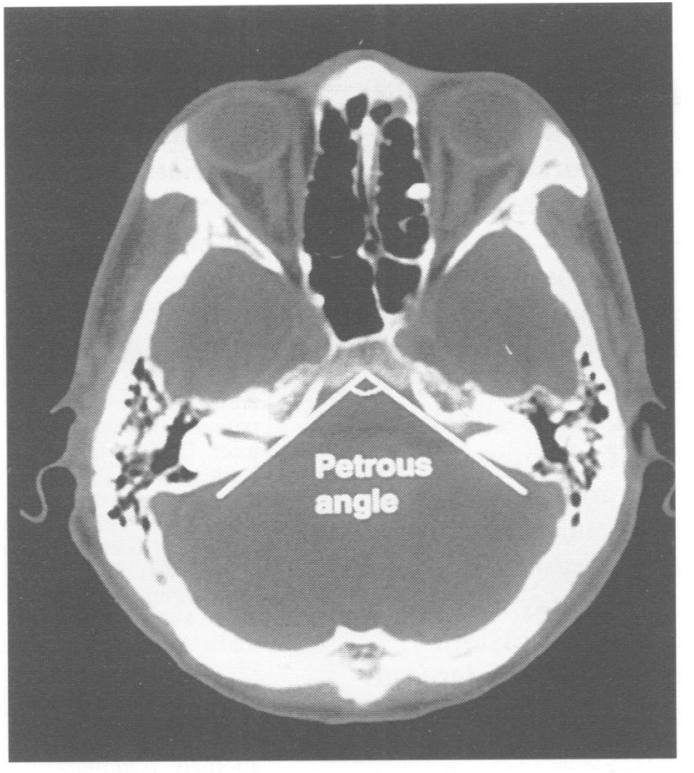

A

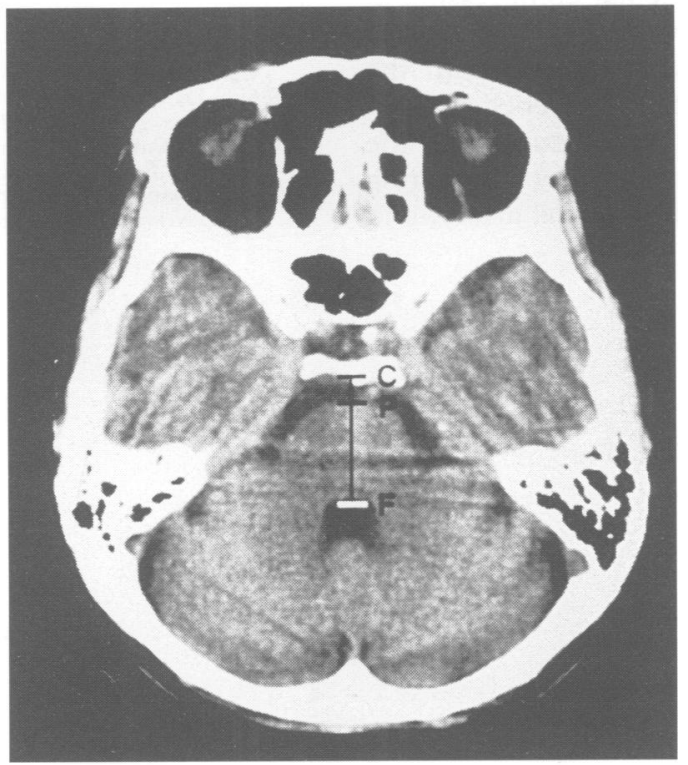

$\mathrm{B}$

petrous bones at the level of the internal auditory meatuses (figure, A).

As another index to evaluate the narrowness of the posterior fossa, we employed the pons diameter index, which was originally used to assess the severity of brainstem atrophy in cases of persistent vegetative state. ${ }^{7}$ The distance between the posterior surface of the clivus and the floor of the fourth ventricle (CF) and the distance between the ventral surface of the pons and the floor of the fourth ventricle (PF) were measured along the midline on a CT slice $10 \mathrm{~mm}$ above the level of internal auditory meatuses, and the pons

Petrous angle and pons diameter index in the control and hemifacial spasm groups

\begin{tabular}{|c|c|c|}
\hline & $\begin{array}{l}\text { Petrous angle } \\
\text { Mean (SD) (05\% CI) }\end{array}$ & $\begin{array}{l}\text { Pons diameter index (\%) } \\
\text { Mean }(S D)(95 \% \mathrm{CI})\end{array}$ \\
\hline $\begin{array}{l}\text { Control group }(n=33) \\
\text { Hemifacial spasm group }(n=34)\end{array}$ & $\begin{array}{l}106 \cdot 1(7 \cdot 1)(103 \cdot 6-108 \cdot 7) \\
101 \cdot 5(9 \cdot 2)^{\star}(98 \cdot 2-104 \cdot 8)\end{array}$ & $\begin{array}{l}85 \cdot 7(5 \cdot 1)(83 \cdot 9-87 \cdot 5) \\
90 \cdot 1(4 \cdot 3)^{\star \star}(88 \cdot 6-91 \cdot 7)\end{array}$ \\
\hline
\end{tabular}

$\star \mathrm{P}<0.05 ;{ }^{\star} \mathrm{P}<0.001 v$ control group (Student's $t$ test). diameter index was calculated as $\mathrm{PF} / \mathrm{CF} \times$ 100 (\%) (figure, B). Measurement of the pons diameter index was not employed at the level of internal auditory meatuses, because the ventral surface of the pons could not be clearly recognised due to artifacts.

We did not use contrast enhanced CT in the present study because enhancement of the basilar artery and dura could interfere with accuracy of the measurements by making it difficult to identify the posterior surface of the clivus or the ventral' surface of the pons. All the measurements were made by one blind observer to eliminate between observer variability.

\section{Results}

The petrous angle and pons diameter index were compared between the control and hemifacial spasm groups (table). The petrous angle in the hemifacial spasm group was smaller than that in the control group, and the difference was significant $(P<0.05)$, indicating that the elevation of the petrous bone toward the cerebellopontine angle cistern in the hemifacial spasm group is more prominent than in the control group. In addition, the pons diameter index in the hemifacial spasm group was greater than that in the control group, and the difference was also significant $(P<0.001)$, indicating the severity of narrowing of the posterior fossa in the hemifacial spasm group. These results indicate that the cerebellopontine angle cistern of patients with hemifacial spasm is narrower, resulting in a more crowded condition of cranial nerves and vascular structures compared with patients without hemifacial spasm.

The petrous angle and pons diameter index were also compared between the male and female patients in the control group. No significant differences were detected, but the petrous angle of the women tended to be smaller than that of the men (men 107.9 (SD 5.1); women $105 \cdot 3(\mathrm{SD} 7 \cdot 6)$ ).

\section{Discussion}

Hemifacial spasm is a motor counterpart of trigeminal neuralgia, ${ }^{4}$ both of which are caused primarily by vascular compression of the root exit zone of the nerves. Several authors have shown that trigeminal neuralgia can also be caused by compression of the nerve by distorted petrous bone. ${ }^{4}$ Smith and Mumford ${ }^{8}$ measured an angle of the petrous bone at the site where it is crossed by the trigeminal nerve by using impression techniques to produce a plaster model of the bone, and considerable variations were found. They speculated that these variations could be a factor in the genesis of trigeminal neuralgia. Similarly, petrous bone anomalies are considered to be a causative factor in some patients with hemifacial spasm. Tanaka et al ${ }^{5}$ have reported a patient with abnormal elevation of the petrous bone presenting as hemifacial spasm. In this patient the facial nerve was compressed by the anterior inferior cerebellar 
artery which was displaced by the elevated petrous bone. Nishi et $a l^{6}$ have reported that a patient with a large acoustic neurinoma displacing the brainstem had contralateral hemifacial spasm, which was ameliorated by total removal of the contralaterally located tumour. Both the abnormal elevation of the petrous bone and the contralateral mass lesion displacing the brainstem cause the cerebellopontine angle cistern to be tight and crowded with cranial nerves and vascular structures, which in turn is considered to increase the chance of vascular compression of the facial nerve. ${ }^{9}$ The results of the present study indicate that the degree of normal variation in narrowing of the posterior fossa as evaluated by the petrous angle and pons diameter index may also affect the chance of neurovascular compression.

Neurovascular compression is considered to be generated by elongation, tortuosity, or dilatation of normal or normal variant arteries. Carlos et al $^{9}$ described several anatomical variations of the posterior fossa arteries which may increase the chance of vascular compression of the facial nerve. These variations include (1) common trunk anomalies in which both the anterior and posterior inferior cerebellar arteries originate from a common trunk, (2) the posterior inferior cerebellar artery originating from high portions of the vertebral artery, and
(3) the anterior inferior cerebellar artery with a proximal branching pattern.

It is concluded that the narrowness of the cerebellopontine angle cistern together with these variations of vascular anatomy are possible factors facilitating neurovascular compression in hemifacial spasm.

1 Jannetta PJ, Abbasy M, Maroon JC, Ramos M, Albin MS Etiology and definitive microsurgical treatment of hem facial spasm: operative techniques and results in 47 patients. $\mathcal{F}$ Neurosurg 1977;47:321-8.

2 Barker II FG, Jannetta PJ, Bissonette DJ, Shields PT, Larkins MV, Jho HD. Microvascular decompression for hemifacial spasm. $\mathcal{F}$ Neurosurg 1995;82:201-10.

3 Clarke CRA, Harrison MJG. Neurological manifestations of Paget's disease. $\mathcal{F}$ Neurol Sci 1978;38:171-8.

4 Gardner WJ, Dohn DF. Trigeminal neuralgia-hemifacia spasm-Paget's disease: significance of this association. spasm-Paget's disease:
Brain 1966;89:555-62.

5 Tanaka A, Tanaka T, Irie Y, Yoshinaga S, Tomonaga M. Elevation of the petrous bone caused by hyperplasia of the occipital bone presenting as hemifacial spasm: diag nostic values of magnetic resonance imaging and threedimensional computed tomographic images in a bone anomaly. Neurosurgery 1990;27:1004-9.

6 Nishi T, Matsukado Y, Nagahiro S, Fukushima M, Koga $K$. Hemifacial spasm due to contralateral acoustic neuroma: case report. Neurology 1987;37:339-42.

7 Nakamura Y, Nakatsukasa M, Ibata Y, Yamaki JT, Ohira $\mathrm{T}$, Takase $\mathrm{M}$, et al. Clinicophysiological study of multimodality evoked potentials and CT findings in persisten vegetative state. Brain and Nerve 1988;40:341-50.

8 Smith DG, Mumford JM. Petrous angle and trigeminal neuralgia. Pain 1980;8:269-77.

9 Carlos R, Fukui M, Hasuo K, Úchino A, Matsushima T Tamura S, et al. Radiological analysis of hemifacial spasm with special reference to angiographic manifestaspasm with special reference to angiogra
tions. Neuroradiology 1986;28:288-95. 